\title{
The Urban Heat Island Analysis of Changsha-zhuzhou-xiangtan Urban Agglomeration Aased on Modis Data
}

\author{
Jiao Yuan ${ }^{1,2,}$,Jingwen $\mathrm{Li}^{1,2}$,Suxian $\mathrm{Ye}^{1,2}$,Xiaoqiang $\operatorname{Han}^{1,2}, \mathrm{Yao} \mathrm{Hu}^{1,2}$ \\ ${ }^{1}$ Guilin University of Technology, Guilin, Guangxi ,China \\ ${ }^{2}$ Guangxi Key Laboratory of Spatial Information and Geomatics, Guilin,Guangxi ,China
}

\begin{abstract}
Using a spatial resolution of MODIS land 1000m standard products ,we can get the Land Surface Temperature.Researching for the Land Surface Temperature including spatial and temporal distribution characteristics influence factors.The results show that Spring,Summer and Autumn temperatures mainly concentrated in the central region, Winter temperature mainly concentrated in the South region.From 2001 to 2015 , the maximum temperature difference is summer daytime and the difference is $17.58^{\circ} \mathrm{C}$, the minimum temperature difference is autumn daytime and the difference is $11.3^{\circ} \mathrm{C}$. According to the thermal field intensity distribution,compared 2005 with 2015,Urban Heat Island intensity gradually increased in 2015, the high temperature area increased and distributed more concentrated,and diffusion weakened from the city to the surrounding,the urban heat field is higher than the thermal field.That index by calculating the thermal landscape,account for a dominant position in the middle of heat distribution, and all types index in 2015 are higher than in 2005.
\end{abstract}

\section{Introduction}

With the intensification of urbanization and industrialization, the area and scope of urban construction land is expanding, which makes the city have a phenomenon that the urban temperature is higher than the suburban temperature, called the "heat island effect", it is affected by the urban landscape type and the impact of urban spatial patterns ${ }^{[1-4]}$.

\section{Research methods}

\subsection{Data collection}

The MODIS data used was downloaded from the LAADS Web ${ }^{[5]}$.The data of the four seasons of 2001, 2005, 2010 and 2015 were selected to analyze the seasonal and interannual variations of urban surface temperature in the Changsha, Zhuzhou and Xiangtan areas in the past 15 years, and the distribution of urban island heat island characteristics was obtained.

\subsection{Data preprocessing}

After obtaining the remote sensing image, it is first subjected to radiation calibration, atmospheric correction and other pretreatment;Then, the monthly maximum, seasonal average, and annual average data are synthesized for the surface temperature data, and the composite results are shown in Fig.1.

MODIS's conversion formula is ${ }^{[6]}$ :

"Corresponding author: 546940102@qq.com

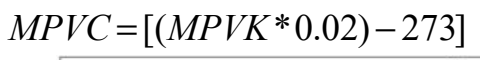

(1)

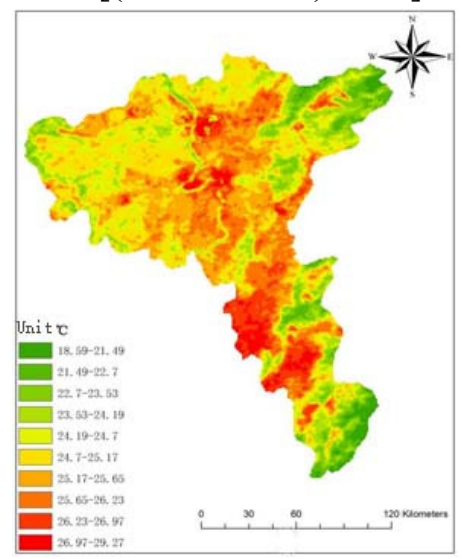

Fig. 1. Four-year average temperature in $2001,2005,2010$, and 2015.

\section{Results and analysis}

\subsection{Analysis of temporal and spatial variation of surface temperature}

\subsubsection{Seasonal variation analysis of surface temperature}

Based on the average of daytime temperature calculations for each season in 2001, 2005, 2010, and 2015, the seasonal average of the corresponding four years, and the seasonal average and range of values for the four seasons are obtained, as shown in Table 1. 
Table 1.Seasonal mean and range of values.

\begin{tabular}{ccc}
\hline season & Daytime average $\left({ }^{\circ} \mathrm{C}\right)$ & Temperature $\operatorname{range}\left({ }^{\circ} \mathrm{C}\right)$ \\
\hline Spring & 25.29 & $19.37-31.68$ \\
Summer & 28.45 & $21.06-38.64$ \\
Autumn & 24.62 & $18.72-30.02$ \\
Winter & 12.66 & $6.26-20.1$
\end{tabular}

Fig. 2 calculates the anomalies for each season based on the daytime average of each season, and the difference results can reflect the difference in surface temperature in the same season in different years.

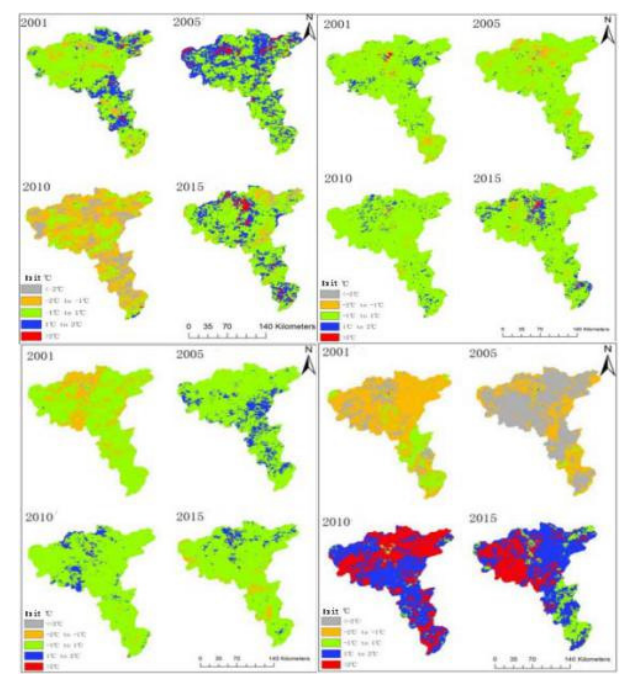

Fig. 2. Four-year spring, summer, autumn, winter difference.

\subsubsection{Analysis of interannual variation of surface temperature}

Table 2 shows the statistically obtained four-year interannual average temperature data and four-day average surface temperature information.

Table 2.Four-year average temperature.

\begin{tabular}{ccccc}
\hline $\begin{array}{c}\text { Year } \\
\left({ }^{\circ} \mathrm{C}\right)\end{array}$ & $\begin{array}{c}\text { Daytime } \\
\text { average }\end{array}$ & Maximum & Minimum & $\begin{array}{c}\text { Standard } \\
\text { deviation }\end{array}$ \\
\hline 2001 & 24.429 & 28.843 & 18.078 & 1.243 \\
2005 & 24.609 & 29.452 & 18.243 & 1.211 \\
2010 & 25.078 & 29.478 & 15.737 & 1.214 \\
2015 & 25.365 & 30.388 & 18.38 & 1.368 \\
AVG & 24.870 & 29.2692 & 18.5904 & 1.199 \\
\hline
\end{tabular}

In order to obtain the variation of the surface temperature between years, the difference calculation is compared, and the result is shown in Fig. 3.

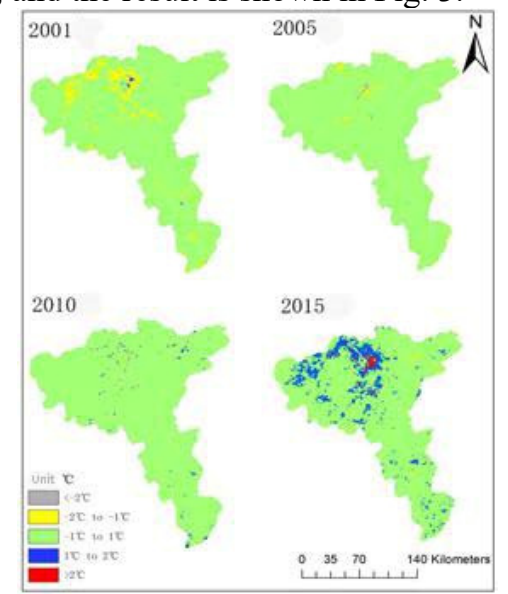

Fig. 3. Four-year average annual difference.

Table 3.Four-year average annual difference.

\begin{tabular}{cccccc}
\hline Year & Decrease $<-2^{\circ} \mathrm{C}$ & Decrease $-2^{\circ} \mathrm{C}$ to $-1^{\circ} \mathrm{C}$ & Change $-1^{\circ} \mathrm{C}$ to $1{ }^{\circ} \mathrm{C}$ & Increase $1{ }^{\circ} \mathrm{C}$ to $2{ }^{\circ} \mathrm{C}$ & Increase $>2{ }^{\circ} \mathrm{C}$ \\
\hline 2001 & $27(0.09)$ & $2214(6.83)$ & $30130(92.94)$ & $34(0.1)$ & $14(0.04)$ \\
2005 & $55(0.17)$ & $365(1.13)$ & $31989(98.67)$ & $10(0.03)$ & 0 \\
2010 & $43(0.13)$ & $60(0.19)$ & $32059(98.89)$ & $256(0.79)$ & 1 \\
2015 & $5(0.01)$ & $223(0.69)$ & $28522(87.98)$ & $3449(10.64)$ & $220(0.68)$ \\
\hline
\end{tabular}

\subsubsection{Thermal field strength analysis}

Heat island intensity is one of the important indicators for heat island effect assessment ${ }^{[7]}$.In order to improve the comparability of remote sensing images, the temperature image maps of 2001, 2005, 2010, and 2015 were normalized, and the normalized formula was ${ }^{[8]}$ :

$$
N i=\frac{T i-T \min }{T \max -T \min }
$$

Density segmentation of normalized results.The classification results are shown in Fig. 4.

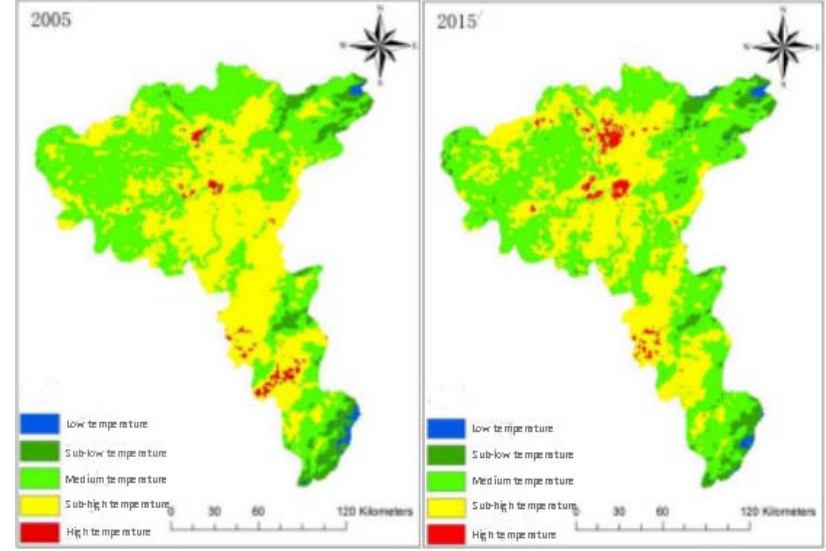

Fig. 4.2005 and 2015 thermal field classification map. 


\subsubsection{Thermal landscape pattern analysis}

Common characterization methods for landscape pattern characteristics include landscape pattern index and spatial statistical methods ${ }^{[9-10]}$. Select the following landscape index to quantify the characteristics.

$$
\begin{gathered}
\mathrm{CA}=\sum_{j=1}^{n} a_{i j} \times \frac{1}{10000} \\
\mathrm{PD}=\frac{n_{i}}{A} \times 10000 \times 100 \\
P L A N D=\sum_{j=1}^{n} a_{i j} / A(100)
\end{gathered}
$$

$$
\begin{gathered}
\mathrm{AI}=\left[\frac{g_{i i}}{\max g_{i i}}\right] \times 100 \\
\mathrm{LPI}=\frac{\max _{j=1}^{n}\left(a_{i j}\right)}{A} \times 100 \\
\text { SHDI }=-\sum_{i=1}^{m} p_{i}^{*} \operatorname{In}\left(p_{i}\right) \\
\text { SHEI }=\frac{-\sum_{i=1}^{m} p_{i}^{*} \operatorname{In}\left(p_{i}\right)}{\operatorname{Inm}}
\end{gathered}
$$

Table 4.Dynamic change of plaque type level index

\begin{tabular}{ccccccc}
\hline TYPE & Year & CA & PD & PLAND & AI & LPI \\
\hline \multirow{2}{*}{ Low temperature zone } & 2005 & 19147.5358 & 0.0005 & 0.6879 & 73.5577 & 0.4226 \\
& 2015 & 16571.6341 & 0.0006 & 0.5953 & 71.7877 & 0.2190 \\
Sub-low temperature zone & 2005 & 175075.4503 & 0.0022 & 6.2895 & 78.7810 & 2.3690 \\
& 2015 & 167862.9256 & 0.0030 & 6.0299 & 75.4253 & 0.2190 \\
Medium temperature zone & 2005 & 1308042.8690 & 0.0038 & 46.9910 & 87.9488 & 25.8398 \\
Sub-high temperature zone & 2015 & 1442161.4827 & 0.0051 & 51.8043 & 87.5855 & 17.0625 \\
& 2005 & 1247423.3163 & 0.0042 & 44.8132 & 89.0262 & 38.1196 \\
High temperature zone & 2015 & 1102485.9156 & 0.0052 & 39.6027 & 85.8366 & 24.8473 \\
& 2005 & 33916.0387 & 0.0013 & 1.2184 & 62.8000 & 0.2622 \\
\hline
\end{tabular}

Table 5.Dynamic change of landscape level index.

\begin{tabular}{cccc}
\hline Year & LPI & SHDI & SHEI \\
\hline 2005 & 38.1196 & 0.9765 & 0.6067 \\
2015 & 24.8473 & 0.9847 & 0.6118 \\
\hline
\end{tabular}

\section{Conclusion and discussion}

Through the research in this paper, we can draw the following conclusions:

According to the four-year average temperature map of the study area, the thermal field intensity in spring, summer and autumn is weakened from the center of the city to the periphery, and the trend from the north to the south is weakened and then weakened. The winter high temperature area is mainly concentrated in the central and southern regions. The thermal field strength is the strongest.

\section{Foundation items}

1.Development and Application of Intelligent Security Early Warning System for Visitors in Smart Scenic Areas and Time-Space Virtual Reconstruction Technology.Item Number: 20170220

2. Research on Intelligent Indoor Positioning Method Based on WIFI and Its Application.Item Number: 2018-B-02

\section{References}

1. Howard L,Climate of London deduced from meteorological observation,Harvey and Darton $\mathbf{1}$ (1833)

2. J.Y. Hu, Q.J. Zhu, Progress in urban heat island research , Journal of Beijing Normal University(Natural Science) 46(2010)

3. W.Z. Yue, J.H. Xu, Study on the Ecological Environment Effect of Urban Land Use Based on Remote Sensing Image_-Taking Urban Thermal Environment and Vegetation Index as Examples, Acta Ecologica Sinica, 26 (2006)

4. A.D. Gong, J. Xu, Overview of urban heat island research methods, Journal of Natural Disasters 17 (2008)

5. R.G. Liu, Y. Liu, Research progress in MODIS scientific data processing,Natural science progress 2(2009)

6. P.F. Wu, M.J. Wang, Distribution Characteristics of Urban Heat Island Effect in Beijing Based on Normalized Building Index , Ecology and Environmental Sciences 18(2009)

7. L.G. Li, H.B. Wang, Strength characteristics and grade division of urban heat islands in Liaoning Province, Chinese Journal of Applied Ecology 23 (2012) 
8. D. Yu, W.J. Zhou, Surface temperature inversion and its temporal and spatial variation characteristics in Dongting Lake area, Ecology and Environmental Sciences 23(2014)

9. Y. Bai, H. Meng, Study on the Evolution Characteristics of Urban Heat Island Landscape Pattern in Shanghai, Environmental Science \& Technology 36(2013)

10. S. Xu, F.X. Li, Analysis on the evolution of thermal landscape spatial pattern in Changsha City,Acta Ecologica Sinica 35(2015) 